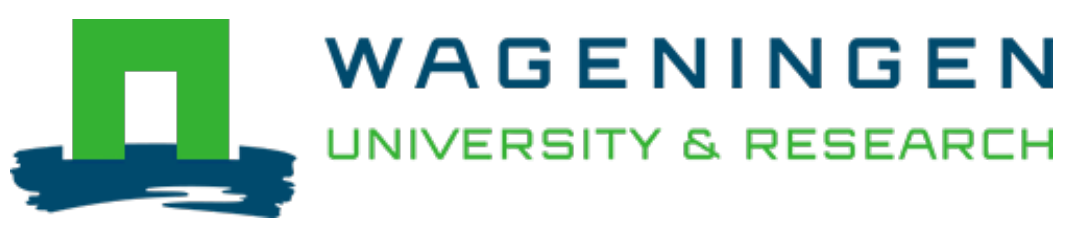

\title{
The future(s) of digital agriculture and sustainable food systems: An analysis of high-level policy documents
}

\author{
Ecosystem Services \\ Lajoie-O'Malley, Alana; Bronson, Kelly; Burg, Simone; Klerkx, Laurens \\ https://doi.org/10.1016/j.ecoser.2020.101183
}

This article is made publicly available in the institutional repository of Wageningen University and Research, under the terms of article $25 \mathrm{fa}$ of the Dutch Copyright Act, also known as the Amendment Taverne. This has been done with explicit consent by the author.

Article 25 fa states that the author of a short scientific work funded either wholly or partially by Dutch public funds is entitled to make that work publicly available for no consideration following a reasonable period of time after the work was first published, provided that clear reference is made to the source of the first publication of the work.

This publication is distributed under The Association of Universities in the Netherlands (VSNU) 'Article $25 \mathrm{fa}$ implementation' project. In this project research outputs of researchers employed by Dutch Universities that comply with the legal requirements of Article $25 \mathrm{fa}$ of the Dutch Copyright Act are distributed online and free of cost or other barriers in institutional repositories. Research outputs are distributed six months after their first online publication in the original published version and with proper attribution to the source of the original publication.

You are permitted to download and use the publication for personal purposes. All rights remain with the author(s) and / or copyright owner(s) of this work. Any use of the publication or parts of it other than authorised under article $25 \mathrm{fa}$ of the Dutch Copyright act is prohibited. Wageningen University \& Research and the author(s) of this publication shall not be held responsible or liable for any damages resulting from your (re)use of this publication.

For questions regarding the public availability of this article please contact openscience.library@,wur.nl 


\title{
The future(s) of digital agriculture and sustainable food systems: An analysis of high-level policy documents
}

\author{
Alana Lajoie-O'Malley ${ }^{\mathrm{a}}$, Kelly Bronson ${ }^{\mathrm{a}}$, Simone van der Burg ${ }^{\mathrm{b}}$, Laurens Klerkx, \\ ${ }^{a}$ School of Sociological and Anthropological Studies, University of Ottawa, Ottawa, Ontario K1N 6N5, Canada \\ ${ }^{\mathrm{b}}$ Wageningen Economic Research, Wageningen University and Research, The Netherlands \\ ${ }^{c}$ Knowledge, Technology and Innovation Group, Wageningen University, The Netherlands
}

\section{A R T I C L E I N F O}

\section{Keywords:}

Digital transformation

Agriculture 4.0

Directionality

Future visions

Normative orientation

Food security

Frame analysis

\begin{abstract}
A B S T R A C T
Ecosystem services delivery is influenced by food systems and vice versa. As the application of digital technologies in agriculture continues to expand, digital technologies might affect the delivery of ecosystem services in view of the sorts of food systems in which they are embedded. The direction food systems develop towards the future, and the role digital technologies play in this development, is influenced by imaginings, hopes and visions about what these technologies mean for future food systems. In this article, we investigate what roles are being imagined for these technologies by international actors with the ability to influence the future of food systems. We analyze outward-facing policy documents as well as conference proceedings on digital agriculture produced by the World Bank, the UN Food and Agriculture Organisation (FAO), and the Organisation for Economic Cooperation and Development (OECD). Using qualitative textual analysis, we show that these organisations envision future food systems that prioritize maximizing food output through technology. We illustrate how this vision reflects a long-standing narrative about the role of technology in food systems innovation, which makes the controversial assumption that increases in food production lead to improvements in food security. Based on this finding, we suggest that evaluations of how digital agricultural technologies might affect the delivery of ecosystem services must begin by considering what visions of future food systems are take into account in science, technology development and policy making. Supporting similar research on high-level narratives surrounding agroecology and climate smart agriculture, we find that the dominant narrative in our dataset supports the status quo global, industrial agriculture and food system. This system continues to be criticized by many scholars for its environmental impacts. Based on our findings, we suggest that ecosystems service researchers could contribute substantially to the evaluation of environmental impacts of digital agriculture by analyzing the impact digital agriculture may have on the trade-offs between provisioning, regulatory, and cultural ecosystem services for several different food system futures. Such analyses can feed into processes of responsible innovation.
\end{abstract}

\section{Introduction}

Ecosystem services delivery is influenced by food systems and vice versa (Cruz-Garcia et al., 2016). It has been argued that the application of digital technologies such as sensors and intelligent machines to agriculture may represent a sub-driver of ecosystem service benefits and changes related to food production (Rounsevell and Harrison, 2016); however, evidence on the effects of precision technologies on ecosystem integrity is not yet conclusive. Many articles with a technological focus (El Bilali and Allahyari, 2018; Hunt and Daughtry, 2018; Kamilaris et al., 2017; Mogili and Deepak, 2018; Patrício and
Rieder, 2018; Shamshiri et al., 2018; Skvortcov et al., 2018; Smith, 2020; Verdouw et al., 2016; Weersink et al., 2018; Zhao et al., 2019) emphasize the potential positive impacts of digital agriculture, but this emphasis may be the result of hype rather than concrete evidence that digital agriculture will deliver on its promises (Klerkx and Rose, 2020) and has raised skepticism among critics (Clapp and Ruder, 2020). Nevertheless, academics and policy-makers are describing an ongoing paradigm shift in food production-a radically new model of producing food, where data-driven decisions help reduce the use of harmful or scarce inputs (McBratney et al., 2005; Rossel and Bouma, 2016). Some researchers have preliminarily tested the ecosystem and food security

\footnotetext{
* Corresponding author.

E-mail addresses: Alana.Lajoie-O'Malley@uottawa.ca (A. Lajoie-O'Malley), kbronson@uottawa.ca (K. Bronson), simone.vanderburg@wur.nl (S. van der Burg), laurens.klerkx@wur.nl (L. Klerkx).
} 
gains from digitalization (Akhtman et al., 2017), while others are beginning to think through their potential social and ethical consequences (Klerkx et al., 2019; van der Burg et al., 2019). Such issues include: (a) data ownership, accessibility, sharing and control (Eastwood et al., 2019; Jakku et al., 2019) (b) power distribution in the food system (Bronson, 2019, 2018; Carolan, 2017; Rotz et al., 2019), and (c) impacts on human life and society (van der Burg et al., 2019). However, it is still uncertain what the future of digital agriculture will look like (Klerkx and Rose, 2020; Clapp and Ruder, 2020), who will benefit from digital agriculture, and how it will affect agricultural production and food systems at large, including the delivery of ecosystem services.

Given this uncertain future, this requires scrutinizing assumptions about the role these technologies will play in the food systems of the future. Imaginings of applications of technology and hopes for the future drive innovation (Berkhout, 2006; Borup et al., 2006; Jasanoff and Kim, 2015); futures are not inevitable, but are the result of human decision-making and action. They shape, and are shaped by, technical projects as well as by existing predictions, dreams and imaginings about those projects (Gidley, 2017). Such imaginings and hopes are thus key drivers of directionality in the broader innovation systems that support (or conversely, do not support) transformative change towards sustainable future food systems (Hekkert et al., 2020; Klerkx and Rose, 2020; Pigford et al., 2018; Klerkx and Begemann, 2020). The important performative role of frames and imaginings by agri-food tech companies, farmers and their advisors, and in farming and food media outlets has already been noted for several so-called Agriculture 4.0 technologies such as digital agriculture, vertical farming, gene editing and cellular agriculture (Chiles, 2013; Mouat et al., 2019; Kuch et al., 2020; Barrett and Rose, 2020; Broad, 2019; Broad, 2020a; Broad, 2020b; Klerkx and Rose, 2020; Clapp and Ruder, 2020). These authors note that such frames and imaginings are often about raising positive expectations and hype and display what has been called 'agri-food tech solutionism' (Fairbairn and Guthman, 2020), but may downplay negative social, environmental, economic, health, nutrition, and food justice effects and overestimate agricultural viability and feasibility of these Agriculture 4.0 technologies.

We must also ask, then, what roles are being imagined for digital technologies by international actors who impact the future of food by influencing the funding, design, governance, and implementation of digital agricultural innovation. It is from this starting place that we take our cue from other scholarship that has treated high-level policy documents as powerful spaces for such imagining (Karlsson et al., 2018; Poppe et al., 2015; Tomlinson, 2013). We consider how three major international organisations envision the future of digital agriculture, ask what sort of current and future food system that engenders, and reflect on what ecosystem services researchers might contribute to the evaluation of these technologies and the futures they are imagined to inhabit. We analyze outward-facing policy documents as well as conference proceedings on digital agriculture produced by the World Bank, UN (namely, Food and Agriculture Organisation) and Organisation for Economic Cooperation and Development (OECD). Using a thematic analysis of texts produced by these organisations, we detail the role these organisations imagine for digital agricultural technologies in the food systems of the future. The analysis was guided by four research questions: 1) What vision of the future is presented in the documents? 2) What digital technological forms and configurations appear in the documents? 3) What food system actors are represented in the documents? 4) Which food production strategies are represented in the documents?

Supporting similar research on high-level language surrounding agro-ecology and climate smart agriculture (Pimbert, 2015), we find that descriptions of digital agricultural futures found in our dataset embed dominant and long-standing stories - what have been called "master narratives" (Macnaghten et al., 2015) that prioritize maximizing food output through technology. We illustrate how this vision reflects a long-standing narrative about the role of technology in food systems innovation, which makes the controversial assumption that increases in food production lead to improvements in food security. This dominant narrative supports the status quo industrial agriculture and food system, which is by now heavily critiqued for its environmental impacts. Given this result, we suggest that ecosystems service researchers could contribute substantially to the evaluation of digital agriculture technologies by analyzing the impact digital agriculture may have on the trade-offs between provisioning, regulation and maintenance, and cultural ecosystem services for several different food system futures.

\section{Background: Digital agriculture and food system sustainability}

While computers and global positioning system technologies have been used in food production for decades, agriculture is predicted to be undergoing a more fulsome digitalization under the application of sensors for collecting data and intelligent machines for mining them. For instance, John Deere tractors now passively collect data on a host of farm-level environmental variables (e.g. soil $\mathrm{pH}$ and moisture). Data from all tractor users get aggregated by a partner corporation that deploys computer algorithms for searching across these big data and generating advice for farmers on when to plant, seed, and spray. Today, farm equipment that embeds data collection sensors is called precision equipment. These tools are so titled because, when used in conjunction with GPS, the data are thought to facilitate decision-making via accurate prediction and modeling. Data, for example, can be used to point to specific areas of a field in need of attention (Poppe et al., 2015; Sonka, 2015).

The reduction of scarce (e.g. water) or harmful (e.g. chemicals) agricultural inputs made possible through precise on-farm decisions has been linked to improved agricultural ecosystems. A 2004 literature review of academic work on precision agriculture (PA) "confirm[ed] the intuitive idea that PA should reduce environmental loading by applying fertilizers and pesticides only where they are needed, and when they are needed" (Gebbers and Adamchuk, 2010, p. 823). As is the case in this example, most studies of digital agriculture examine its environmental impact only theoretically, by assuming a reduction in chemical use under sensors and data equates with overall environmental gain (Akhtman et al., 2017). Some studies point to broader sustainability gains from digital agriculture, such as ethical human and non-human animal relations on dairy farms (Scholten et al., 2013). Academic and popular literature on digital agriculture identifies a link between precise information gleaned from big data and environmentally sound management. This link is often presented to be so profound that it represents a paradigm shift from production-based agricultural goals to sustainability. Some view this as a radical shift toward food production decisions which "substitute knowledge for physical inputs" (Bongiovanni and Lowenberg-DeBoer, 2004, p. 359):

Last century, during the 'Green Revolution' the use of synthetic fertilizers contributed to increased agricultural production. However, their use did not reflect local soil and water conditions because recommendations were developed for larger agro-ecological zones. They only focused on increased productivity, neglecting any adverse environmental consequences. ... Using soil sensors in agriculture can fundamentally change this approach by allowing innovative 'bottom-up' approaches that characterize local soil and environmental conditions in space and time, improving the efficiency of production to maximize farm incomes and minimize environmental side effects (Rossel and Bouma, 2016, p. 71).

Indeed, Bayer/Monsanto's head of digital farming suggests that the corporate goal of maximizing profit via the sale of chemical and seed inputs will be replaced by the goal of selling positive social and environmental outcomes through the sale of big-data generated information: 
Before, selling more products meant more business for a company like Bayer; whereas in future, the fewer products we sell the better, because we're selling outcome-based services. With sensor devices, we can learn a lot more about what is and is not helping crops and livestock and create a better way of doing things (Maity, 2018, p. n.p.).

This paper takes up these kinds of expectations for the future of digital agriculture as a subject of thematic analysis. Rather than taking up a view of technological change which sees the future as predetermined by innovations that bring harm (dystopias) or help (utopias) (Smith and Marx, 1994), we treat the future as an ongoing project that is still taking shape under the influence of human thoughts and actions taken in the present. We consider how documents produced by the World Bank, the Organisation for Economic Cooperation and Development (OECD) and the Food and Agricultural Organisation of the United Nations (FAO) imagine this future. We choose documents from these three organisations in particular because other researchers have identified them as providing essential imaginative resources that influence policy and private sector decision-making about food systems. For example, Tomlinson (2013) performed a discourse analysis on what she called the "international policy arena of food security" (p. 81). She identifies key framing devices in this analysis, describing frames as an interpretive schema that helps signify and condense the world (Snow and Benford, 1992) in ways that are particularly useful to policymakers tasked with reducing ambiguity and making decisions (Hajer and Laws, 2006). Similarly, Karlsson et al. (2018) focus on high-level debates around Climate Smart Agriculture (CSA), with a particular focus on how different actors frame CSA as it is intended to tackle the problems associated with changing environmental resources.

\section{Method}

We searched World Bank (Open Knowledge Repository), FAO (FAO.org/documents), and OECD (OECD iLibrary) document repositories. Importantly, these repositories are not bibliographic databases. They do not include meta-data information that enables importing search results into citation management software such as EndNote or into systematic literature review software such as Covidence. While two of the three search engines (World Bank and OECD) identified a specific number of search results for search queries, the FAO's search engine indicated only the approximate number of documents yielded by each query (i.e. 'about 6576 results'). In all cases, search results were displayed by relevance.

Our search query was defined as follows; "precision agriculture" OR "digital agriculture" OR ("Big Data" AND "Agriculture") OR (technology AND agriculture) OR (ICT AND agriculture). The searches were restricted to documents published between 2015 and 2018 and to documents published in English. This time frame was selected because it begins with two key textual events: a World Bank document entitled the "Future of Food" (Klytchnikova et al., 2015), which according to their own metrics has received almost 5000 downloads, and an OECD Global Forum on Agriculture specifically on "digital technologies" held in May 2018. Given the relevance of this OECD forum, its proceedings were included in the dataset even though they are not part of the OECD publication repository (since proceedings are not formal publications). Each repository offered different options for further restricting the dataset (e.g. search by title). Based on these options, these search terms were applied to the entirety of the World Bank's repository (i.e. no option for restricting to titles or abstracts) yielding 317 results; to titles and abstracts in the OECD's repository yielding 50 results; and initially to all fields in the FAO repository. For the FAO repository, the search terms applied to all fields yielded "about 6576 results". A spot check of these results revealed that over $90 \%$ of them were not relevant. It also revealed many duplicate results. The same search terms applied to titles and key words as well as to titles or keywords yielded zero results. As such, and to maintain a consistent search query with the other two sources, the large set of FAO documents was retained and a modified screening method was applied to them, as described below (see Fig. 1).

Because of the nature of the search engines within the document repositories, it was necessary to review search results manually. Author number one screened for eligibility using the titles, abstracts, and sections of documents highlighted as relevant to the search terms by each organization's search engines according to one criterion: that the document address both digitalization and agriculture. Given the large number of results from the FAO, and given that over $90 \%$ of these results were clearly either irrelevant or duplicates, only the first 1000 FAO results were screened for relevance; the last 200 of these results yielded no new relevant documents and the incidence of duplicate documents was high. As this was not intended to be a systematic literature review, but instead a qualitative textual analysis this approach yielded the results required to meet our research aims. To further confirm the reliability of these search terms, author number one manually reviewed the entirety of the publication repositories for 2018 and spot-checked the entirety of publication lists for the remainder of the selected time frame (2015-2018). No new documents resulted from this quality-check. This process eliminated documents that came up in the searches because they included a relevant word or phrase in a footnote even though the main text was about topics unrelated to agriculture or digitalization. This preliminary screening resulted in an initial sample of 148 documents for closer examination. This final sample of texts range from short policy briefs to $300+$ page reports (see Appendix 1).

If a document was determined to be eligible as a result of the first screening step, the full text of the document was immediately examined according to two additional criteria: (i) publications deal substantively with agriculture (i.e. for the purposes of this study we were not concerned with how digital agriculture might be mentioned briefly in publications that primarily addressed a different subject) and (ii) publications discuss these innovations as applied at the point of production, as opposed to at other points along the food system or supply chain. This involved eliminating documents that made passing reference (i.e. less than two sentences) to digital agricultural tools as well as documents that discussed, for instance, blockchain applications in agri-food contracts, the use of digital tools for achieving access to finance, and other applications of digital technologies in food systems beyond the point of production. Documents that included discussion of digital technologies at both the point of production and at other points along the supply chain were retained so that the sections addressing digital tools at the point of production could be closely analyzed. This selection resulted in a dataset of 23 documents (see Appendix 1) which the first author used to conduct a manual qualitative, inductive thematic analysis (Braun and Clarke, 2006) (see Fig. 1).

This analysis was guided by an interest in future oriented statements - specifically word choices and frames that could elucidate what themes play a role in describing, evaluating, and imagining the future. As indicated in the introduction, a set of research questions was used to guide this thematic analysis: What vision of the future is presented in the documents? What digital technological forms and configurations appear in the documents? What food system actors are represented in the documents? Which food production strategies are represented in the documents? Author number one extracted passages from the texts that address these four questions and sorted these into an inventory of themes. Once developed, she performed word-searches based on these themes throughout the data set to identify and extract further recurrences of these themes. Based on the initial list of emergent themes (see Table 1 in Results below) and using textual excerpts illustrating them, authors number one and two used a consensus-building approach to revise the initial results. They reflected upon and reviewed the most prominent themes in the data set and identified those which only emerged after initial coding was complete. Through this process, they revised the themes and identified synthesizing themes that ran across 


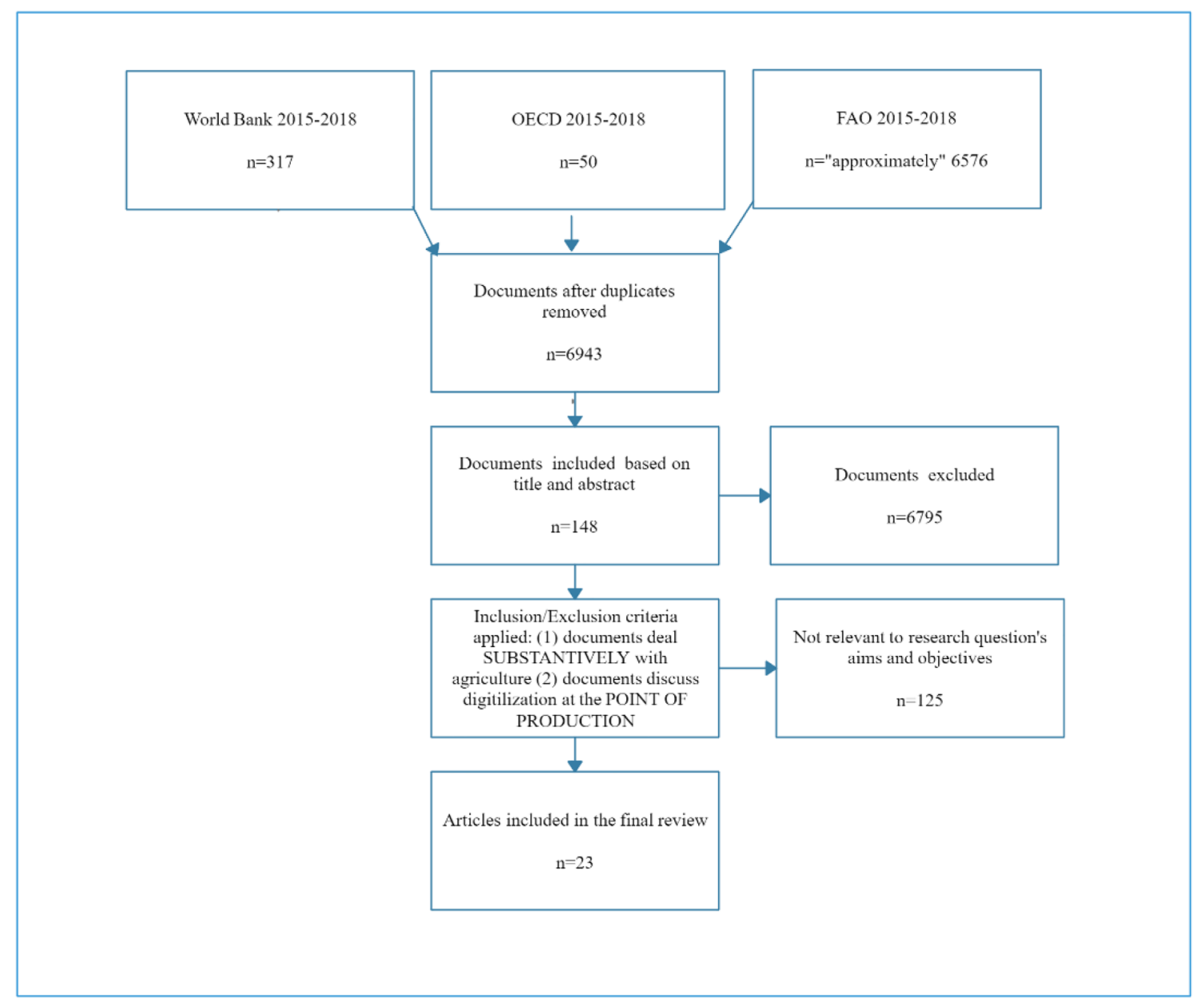

Fig. 1. Documents screened.

the dataset (see Table 2 in Results below). The results were then shared with authors three and four, who contributed to the interpretation of the themes, the formation of the outline of the article, the writing of the discussion and conclusion, and overall editing of the text.

\section{Results}

The analysis yielded three overarching themes outlined in Table 2 and discussed in detail below.

Together, the content of the themes introduced in Table 1 and further synthesized in Table 2 broadly frames agricultural digitalization as a process of technology-led positive change, albeit one dependent on relationships of collaboration and trust between small farmers, technologies, and their private, public, and NGO sector proponents. These actors are envisioned as working together to solve food system and broader social problems. The problem, as framed by the World Bank, the FAO, and the OECD is one of food shortages, exacerbated by ecosystem pressures. Within this frame, the solution is to find technological means of producing more food to meet the needs of a rapidly growing global population. While provisioning, regulation and maintenance, and cultural ecosystem services are not directly discussed in the dataset, digital agriculture is described in ways that suggest a promise of enhanced provisioning as well as regulation and maintenance ecosystem services via the application of new technologies. These enhanced services are envisioned as resulting from digital agriculture's potential to allow farmers to anticipate and predict natural events based on local circumstances and conditions. This potential invites the possibility of simultaneously increasing yields, increasing incomes, and reducing inputs into the environment that might impede ecosystem functions such as nutrient cycling, carbon sequestration, and pest control. This, in turn, is portrayed as increasing food production and therefore food security. We return to these envisioned enhancements to ecosystem services in our discussion. Here, we turn our attention to the future in which these enhancements are imagined to take place.

\subsection{Inevitable agricultural transformations}

A frequent theme among the texts is of inevitable agricultural shifts: digital technologies are leading to positive transformations in the agricultural sector. The message, both implicit and explicit in the texts, is that societies are at risk of not delivering sustainability and food system security if they fail to adopt digital agriculture. A variety of digital agricultural technologies are represented as bringing about major transformations on both large and small farms, from automated equipment to the application of smartphones and datasets crowdsourced from small-scale farmers. The collision or intersection of transformations occurring on small- versus large-scale farms surfaces as a concern raised within some of the texts; there are concerns about the extent to which the transformations brought about through digital agriculture will include or exclude small-scale farmers.

Large and small farms are often addressed separately in the texts. The present and future transformative impacts of precision agricultural tools for large farms are taken for granted. For instance, the FAO says:

Nowadays, farms are transforming into a high-tech enterprises (sic) ... Over the past 20 years the geographic information system (GIS), 
Table 1

Initial Inventory of Themes Based on Research Questions.

What vision of the future is presented? (Optimistic according to organizations)

What vision of the future is presented? (Pessimistic according to organizations)

What particular digital technological forms and configurations?

What particular food system actors?

Which food production strategies?
Future transformed through technology: positive

Farmerless farms

Technologies will help feed a growing population with less land and more environmental pressures Technologies will help predict the future (forecasting, prediction of yields, draughts, weather events etc.) to ease decision-making

Technologies will help control pests

Technologies will help adapt to the fact that historical knowledge is no longer reliable

Technologies will connect smallholder farmers to markets

Technologies will help reduce poverty

Technologies are a driver of development more broadly (multiple social benefits)

Technologies may help localize decision making

Technologies will help address inequities (esp. gender)

Technologies may provide tools for empowering farmers to become more independent

Future transformed through technology: negative

Technologies may deepen the digital divide (and/or triple divide of digital, rural, and gender)

Technologies may exacerbate inequities

Technologies may further consolidate power in large agribusiness

Technologies may serve to further consolidate globalization

Large-scale equipment (i.e. tractors with sensors, GIS)

Distributed tools using smartphones or basic cell phones

Crowd-sourced open data

Crowd-sourced proprietary data

Advisory services

Forecasting services

Bundled services (esp. to incentivize farmers to participate in crowdsourced data)

Localized (geographically)

Localized (linguistically)

Small farms vs. big farms

Poor farmers in global south

Farmers who are slow to adopt new technology

Farmers disadvantaged by not using/having access to technology

Large farms already using new technologies

Private sector investors in low income countries

Private sector service providers

Growth in interest from private sector investors is good

Governments as mediator between other actors

Governments as investors in technologies to guard against digital divide

Governments as monitors of farm data, developers of data-driven programs

Development partners (NGOs) as funders of technology development and implementation

Development partners (NGOs) as users of data for program development, evaluation, and funding

decisions

The public

New technological tools are central to the future of food production

New technological tools need to be useful and/or accessible for smallholder farmers

Smallholder farms are part of food production and should remain part of it

Smallholder farms are a barrier to optimal food production

More food production needs to be paired with strategies for making the food system more efficient

all the way along the supply chain

Technology is not the only answer

It is important to use technology to optimize resources for increased yields and reduced

environmental impact remote sensors and other new tools have moved farming ever further into a technological wonderland. As amazing as today's technologies are, they are just the beginning of the era of modern farming. It is something that is already happening, as large agricultural corporation and farmers collect vast amounts of information on crop yields, soil-mapping, fertilizer applications, weather data, machinery, and animal health (FAO, 2018a, p. 35).

Here and elsewhere, transformations on large farms come from the application of geographic information systems (GIS), sensors, and other tools that enable automation and data-driven decisions through the collection, synthesis, analysis, and dissemination of insights from big data.

Most of the texts also convey that digital tools will inevitably transform small farms. In a report on the application of information and communication technologies for agricultural and rural development concerned explicitly with "smallholder farmers and family farms" (FAO, 2017, p. vii) the FAO says,

Agriculture has undergone many transformations over thousands of years [...] While machines have, largely, replaced the manual plough, modern technology, or e-agriculture applications, hold out great promise as the next transformation in this sector (ibid).

where GIS and remote sensors are represented as the key drivers of transformation on large farms throughout the dataset, it is the ubiquity of mobile phones and related technologies that is predicted to bring similar transformational potential for small-scale farmers. For instance, from a World Bank document with the phrase "seeking opportunities for small farms" in its title:

Digital technology has transformed the way farms and agribusinesses in emerging markets operate - particularly with the everdecreasing cost of owning mobile devices. Already seemingly ubiquitous, it is anticipated that smart phones will have virtually universal coverage, and at that point even the poorest and most remote farm families will have access to diverse digital services and tools (Nielson et al., 2018, p. 30).

This transformation is described as inevitable, as driven by technological innovation, and as "needed" (FAO, 2018b, p. 7). As one World 
Table 2

Revised Inventory of Themes.

Inevitable Agricultural Transformations

The Role of Farmers in Innovation/Trust in People and Technological Progress

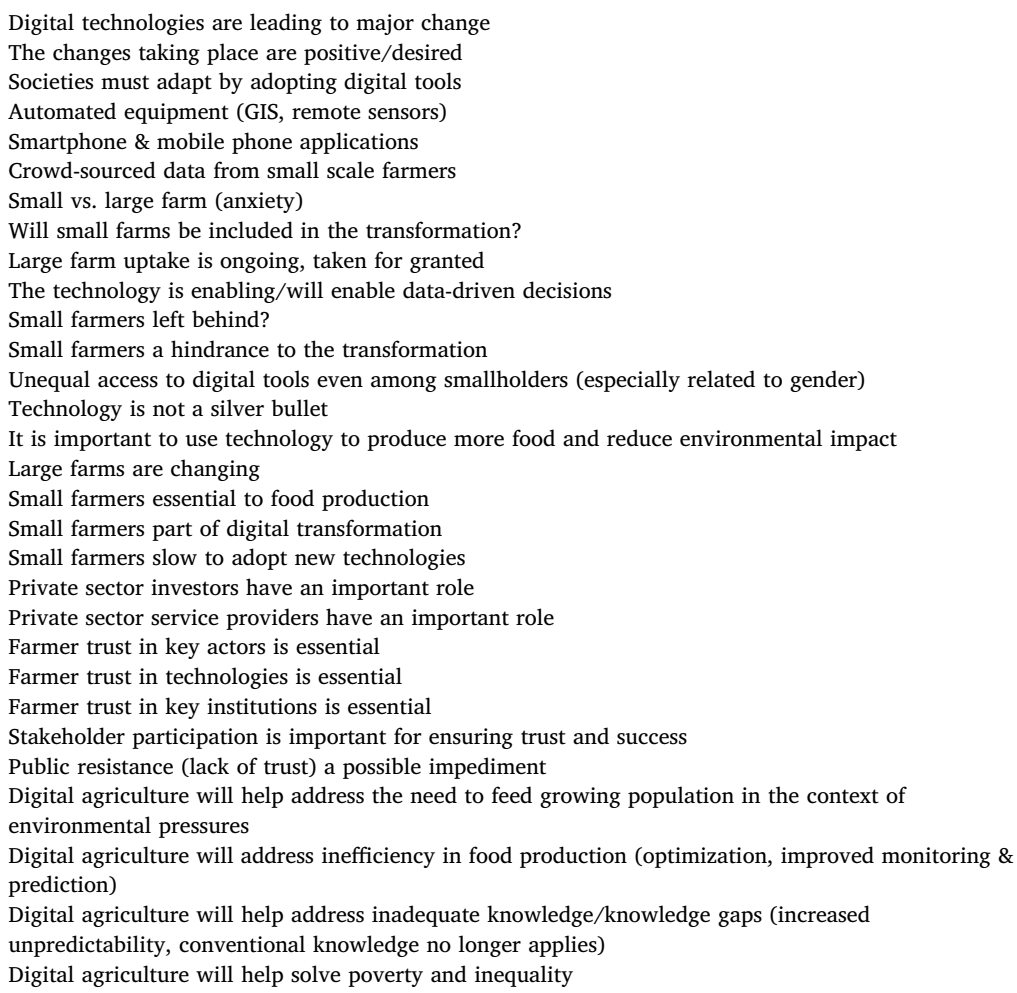

Potential/envisioned solution to food system problems

for instance, reads: "[t]echnology alone is not a silver bullet" (Ghannam, 2017, p. 3). A different World Bank document puts it this way:

The question is whether and how digital technologies can transform agriculture in the way other discrete technologies have transformed the sector, for instance, during Green Revolution. It is unlikely that digital technologies alone would result in another Green Revolution (Nielson et al., 2018, p. 5).

Similarly, in its discussion of strategies for the "transformation" (FAO, 2018b, p. 7) needed in the agricultural sectors, the FAO says,

Going beyond apps, drones or farm machinery, innovation in agriculture involves different social, organisational or institutional processes, ranging from access to markets, credit or extension services to marketing produce in a new way (p. 6).

In this way, some of the documents contrast the digital agricultural revolution with the Green Revolution, which is portrayed as chiefly technological; they suggest that digital tools for food production will need to be implemented alongside digital innovations at other points on the supply chain and - to a lesser extent - social and organisational innovations throughout the food system. Even in these instances, though, a transformation of the food system to increase production is put forward as necessary.

\subsection{The role of farmers in innovation}

Somewhat in contradiction to Inevitable Agricultural Transformations, the texts represent smallholder engagement as essential to the realization of a digital agricultural revolution. Small scale farmers are simultaneously portrayed as foundational to agricultural innovation and as slow to adopt new technologies. On one hand, the World Bank states that "the future of food depends to [...] a great extent on small-scale agriculture," and that "the farmers that the globe 
depends on are primarily smallholders with little access to technology, limited knowledge, and few financial resources" (World Bank, 2017, p. 101). Small-scale producers are "protagonists" (FAO, 2018b, p. 9) in agricultural innovation, and

[f]amily farming remains the predominant form of agriculture in Asia and the Pacific. There are more than $\mathbf{5 7 0}$ million farms in the world of which over 500 million are family-owned. They are responsible for at least 56 percent of agricultural production" (FAO, 2017, p. 1).

A few of the FAO and World Bank documents mention the importance of smallholder farmers participating in innovation-led agricultural transformations. The FAO celebrates a case study called Digital Green, "a technology-enabled means of behavior change communication" (FAO, 2017, p. 7) for its efforts in "community engagement and participation" (p. 3). They comment,

Digital Green has demonstrated that a participatory process of engagement combined with simple technology solutions can enable small-scale farming communities to produce and share information of best practices for improved productivity and sustainable livelihoods (p. 6).

Similarly, the World Bank suggests that decision-makers aim to "understand users and the technology" and "engage in participatory, iterative project design" (World Bank, 2017, p. 62).

Digital tools are often presented in the texts as a means to better engage small-scale farmers to clarify their specific needs concerning agricultural technologies. According to the World Bank,

The need for collaboration cuts across the entire agricultural research process, from the conceptualization of a research program to the application of its results. In agricultural research for development, for example, priorities are often based on the needs of smallscale farmers with very limited resources. ICT is making it easier for research organisations to link with these stakeholders and document and understand their needs (p. 132).

While collaboration and stakeholder engagement appear in the documents, many also suggest farmers ought to trust experts and technologies. A case study given by the FAO, which involves the implementation of a technological platform developed by Tata Consultancy Services (TCS) in India, is representative. The case study names "changing farmers' mindsets so that they could trust in and adopt new technologies" (FAO, 2017, p. 60) as a "key challenge" in implementation efforts. In this case study, such challenges were solved by, among other things, "working with reputed NGOs active in the field and trusted by local farmers" (p. 62). Similarly, conference presenters at an OECD conference highlight that "building trust would facilitate adoption" (OECD, 2018a, p. 3). In a summary of lessons learned in the implementation of ICT in agriculture, the World Bank reflects that leaders "must also operate at local levels, modeling the effective use of a technology and building farmers' trust in its efficacy" (World Bank, 2017, p. 12).

Indeed, many of the texts also mention the importance of farmers' trust in the technologies themselves. As the World Bank puts it,

Technical issues undermine user trust, making the adoption process harder. A tool must offer sufficient services to engage users, and be easy to operate, otherwise it will not be used (World Bank Group, 2016, p. 4).

Elsewhere, the World Bank says,

[T] he key to increasing technology uptake among small and medium farms lies in the trust between users and the relevant technology in achieving the proclaimed goals, including better decision making and timely advice for improved productivity (Nielson et al., 2018, p. 12).
Trust in one technology can, according to the World Bank, also generate trust in others. For instance,

Farmer's Friend's position within a wider information service provided by Grameen and Google affords it greater publicity. As customers use one service to positive effect, they become aware of and begin to trust the other, related services (World Bank, 2017, p. 47).

In this way, the technologies themselves are seen to do part of the work of realizing the digital agricultural revolution. Innovations must be useful and reliable, and they must deliver on their promises. When they do, farmers will adopt more of them (or more farmers will adopt them). Internet and communications infrastructure-specifically network connectivity-must also be trustworthy (in the sense of reliable) according to our documents. According to the FAO, "as part of national ICT strategies, the development and implementation of national eagriculture strategies should seek to provide reliable and affordable connectivity" (Treinen and van der Elstraeten, 2018, p. 17). The World Bank agrees that reliable network connectivity is essential:

The foundation of digital transformation in agriculture is anchored in IT infrastructure that is supremely reliable and that has minimal latency and a stable network connectivity to process big data without a time lapse (Nielson et al., 2018, p. 37).

Many of the texts also discuss possible social and political impediments to the digital agricultural revolution, such as resistance to innovations brought on by value conflicts. The World Bank notes that " $[\mathrm{g}]$ overnments face challenges in aligning the private interests of agricultural businesses with the public interests of small farms and concerned citizens," recognizing that there exist "various perspectives on the sustainability of technologies" (World Bank Group, China Development Bank, 2017, p. 20). According to OECD conference participants, there exists "divergence in views about agricultural data ownership" (OECD, 2018a, p. 3). The proceedings speak of the necessity of working to further "understand how to reconcile private and public good dimensions of data" (ibid) and emphasize within this context that "the issue of how to overcome trust issues on the part of the farmer is again crucial" (ibid). In these same proceedings, "impediments to digitalization" (p. 2) included farmers' lack of skill and understanding, a lack of tools that meet farmers' needs, and farmers' lack of willingness to give up decision-making power to technology and those with knowledge about it (p. 2-3).

It remains ambiguous across the texts what exactly is to be done in instances of divergent public views on digital agriculture. On the one hand, an OECD conference session summary suggests that "policymakers may need to look at how to change attitudes and [...] foster acceptance of 'data-driven agriculture,' including by acknowledging and managing risks" (ibid). On the other hand, this same conference's background note includes a comment that "[r]eaping the benefits of digital technologies in agriculture requires the participation and cooperation of farmers, researchers, private sector, non-profits and government," and that "these actors often have different interests and face different incentives" (OECD, 2018b, p. 2). Along similar lines, the FAO speaks of the values of "participatory planning" (FAO, 2018a, p. 2) emphasizing that an essential purpose of this approach is "improving inter-institutional collaboration, transparency and trust in authorities" (ibid) and describing efforts to have stakeholders "challenge the concept" of developing guides and toolkits aimed at helping countries "mainstream ICTs in agriculture" (ibid).

\subsection{Potential/envisioned solutions to food system problems}

Digital agriculture is positioned throughout the documents as likely to play a significant role in solving the problems of inefficiency in production and inadequate knowledge of environmental systems. Digital agriculture, the texts suggest, can solve the future problem of increased pressure on ecosystems due to climate change and the need to 
feed a growing global population. The texts also suggest that digital agriculture will help solve problems of poverty and inequality. Our documents consistently describe the problem of environmental and population pressures anticipated to make it more difficult to feed the world. In a representative statement, the FAO says,

Current FAO projections indicate that the global population could increase by 2.3 billion people from today's levels, reaching 9.8 billion by 2050 . At the global level, agricultural production and consumption in 2050 are projected to be $60 \%$ higher than today. This has to be achieved in spite of the limited availability of arable lands, the increasing need for fresh water and the impact of climate change. Innovative approaches - including information and communication technologies (ICT) - are needed across the agricultural sector to increase productivity, conserve natural resource, and use inputs sustainably and efficiently (FAO, 2018a, p. xi).

This hopeful perspective of how technology can help solve problems of population pressure on food security and ecosystems comes forward throughout the documents we analyzed.

If population growth and environmental pressures come forward as the problem facing the global food system, precision agricultural technologies are presented as a means to solve this problem by allowing for increased food production and a reduction of harmful or scarce agricultural inputs. According to the World Bank, "[p]recision agriculture is part of the solution to feeding a population that is growing faster than available land supply, while also ensuring the sustainable use of water and energy" (Ghannam, 2017, p. 5). For the OECD, a "growing, higher income and more urbanized population" (OECD, 2016, p. 1) is the reason to make "innovation a priority in order to achieve sustainable productivity growth" (OECD, 2018c, p. 16). Digital technologies are represented as allowing farmers to address the problem of inefficiency through optimization. They can help "optimize crop growth and yields" (World Bank, 2017, p. 108), "optimize the utilization of natural resources" (FAO, 2018a, p. 25), and "optimize [...] use of nutrients" (OECD, 2018c, p. 1). Throughout the documents, this kind of optimization is seen to result in improved ecosystem health alongside increased food production and increased farmer incomes.

The ability to monitor, make visible (map) and predict environmental and agricultural systems is another means by which digital agricultural innovations are envisioned as helping to solve the problem of underproduction. Sophisticated digital tools are sometimes presented as providing a kind of intelligence that far exceeds mere human capabilities. The World Bank explains:

ICT can be used to monitor pest thresholds in integrated pest management, provide relevant and timely information and agricultural services, map agrobiodiversity in multiple-cropping systems, forecast disasters, and predict yields (World Bank, 2017, p. 102).

The technologies will also help with the problem of the climate's unpredictability. They help "forecast disasters, and predict yields" (p. 128). They allow for "[a]utomated predictions" (FAO, 2018a, p. 36). The idea that nature is unpredictable, and a source of risk, is present throughout the dataset. For instance,

Around the world, precipitation patterns, maximum and minimum temperature cycles, etc. have changed differently in each region and the climate is becoming less and less predictable (World Bank, 2015, p. 13).

Risk and uncertainty are embedded in agricultural production: the changing weather and the biological processes make perfect control of processes impossible (FAO, 2018a, p. 35).

For the World Bank, this risk and uncertainty, particularly within the context of a changing climate, means that conventional knowledge about agriculture is no longer adequate. Speaking of a digital advisory tool for rice farmers they say,
By providing farmers with data-driven information for planting decisions, the tool can compensate for the increasing irrelevance of traditional knowledge due to climate variability (World Bank Group, 2016, pp. 2-3).

Along similar lines, an FAO document describes experience and historical knowledge as extraneous:

[Mr.] Awal grew up as an experienced and knowledgeable farmer, having inherited both land and traditional cultivation skills from generations of family members. Whilst such experience and historical knowledge provides him with a firm foundation for cultivation, much of it is extraneous to the modern information society (FAO, 2017, p. 23).

Thus, nature and conventional knowledge are less reliable than knowledge derived using digital technologies. In this sense, data-driven agriculture is seen as helping mitigate the risks to farm productivity caused by a lack of predictability.

When the documents discuss the benefits of digital agriculture, they consistently do so by including benefits that extend beyond food production. These benefits include "increased employment in rural areas," "increased income for rural people," "increased standard of living," "increase in disposable income," "better access to healthcare," "better and cheaper access to credit," "overall environmental conservation," and "positive policy changes" (FAO, 2017, pp. 63-64). The FAO says, " $[\mathrm{g}]$ rowth in the agricultural sector is one of the most effective means of reducing poverty and achieving food security" (FAO, 2018a, p. 1). Despite expressing concern about the digital divide elsewhere, the FAO also says, "[i]t would be hard to overstate the scope for Information and Communications Technologies (ICTs) to drive agricultural and rural development, especially for the poorest smallholders and other households" (Treinen and van der Elstraeten, 2018, p. 1). ICTs in agriculture will,

bridge the rural divide [...] support smallholders and family farmers, fishers, pastoralists, and forest-dwellers [...] increase productivity and profitability, improve consumption of nutritious food, empower youth and women's access to information, technology and markets and ensure that agriculture practices are environmentally sustainable for future generations (FAO, 2018b, p. 11).

Importantly, these comments stand alongside the concerns of a growing digital divide and of small farmers being left behind. As with the other two themes, there are contradictions across the dataset even within documents produced by the same intuition. For instance, the FAO suggests the limitations of an emphasis on increasing food productivity through digital agriculture:

While efforts in the past centered on boosting agriculture to produce more food, today's focus is to tackle the root causes of hunger and malnutrition through transformative changes to our food system (p. 5).

The dataset does include some discussion of social factors that contribute to hunger; however, the dominant narrative remains focused on food production. Digital agricultural innovation will allow us " $[\mathrm{t}] \mathrm{o}$ meet growing food demand from a projected population of close to 10 billion people in 2050 " (p. 4), while also "lifting family farmers out of poverty, tackling unemployment for youth and rural women, and helping the world to achieve food security and the Sustainable Development Goals" (p. 5).

\section{Discussion}

We set out to describe the framings of digital agricultural futures in high level public-facing documents and to understand how these might suggest to decision-makers some of the impacts (positive or negative) of digital agriculture, especially vis-à-vis ecosystem services. Our starting 
premise was that future visions frequently become resources for the appraisal of emergent technologies, which are brought forward to attract funding, develop relevant governance systems, and foster acceptance among users and other actors. Our findings suggest that these organizations have visions of the digital agricultural future that are very positive and which, therefore, endorse major digital transformations in the agricultural system. We have documented how the adoption of digital agricultural technologies is expected to help farmers feed a world that is facing food pressures due to population growth and environmental change, as well as to realize a future of reduced global poverty, reduced environmental harm, and reduced inequality. Central to these expectations is the view that increases in food production will lead to increases in food security, and that digital tools will enable this growth in production in a manner that reduces stresses on ecosystems caused by industrial farming practices.

While there are contradictions and minor narratives in the publicfacing documents that provide nuance to this summary, the dominant vision of a digital agricultural transition reflects some well-practiced optimistic narratives of progress. These positive stories about the future are not unfamiliar but rather are long-standing narratives about food production, environment and society. This finding can be made sense of using MacNaghten et al. (2015), who analyzed textual transcripts of public engagements with nano-technology and argue that the ways social actors describe these technologies have a discursive, social, cultural, and theological "heritage." Inspired by Charles Taylor's use of social imaginaries-or powerful and widely shared ideas which drive social action-MacNaghten et al. suggest that social imaginaries do not arise tabula rasa; instead, they draw on deep-seated stories depicting a normative world (e.g. fairy tale imagery) and are rooted in a shared past. This shared past and imagined future is given shape through what they call "master narratives" around technologies; these narratives recur in the themes and speeches in public discourse that refer to wellknown stories, sometimes even with legendary status (p. 146). Master narratives, every time they are (re)used, "offer references to a shared tradition," meaning that they give expression to a collective way of thinking and, subsequently, a way of life (p. 145).

While our study considers texts and technologies of a different kind than those considered in MacNaghten et al., our findings suggest that master narratives play a similar function here. The themes that came forward in our analysis of the texts published by the World Bank, the FAO and the OECD, frame digital agriculture through a neo-Malthusian and techno-progressivist lens, as the (technical) solution to future food insecurity brought on by population pressures, increasing demand for food, and environmental vulnerability. Given its dominance and stability over time, this framing of the future of digital agriculture could be regarded as a kind of "master narrative" that reflects the dominant framing of food and ecosystem problems. The emphasis on the positive impacts of digital agriculture in a great proportion of the existing scientific literature focused on the technological aspects of digital agriculture may indicate that this master narrative operates in that literature as well. Regardless, if we are, indeed, to understand precision agriculture as a sub-driver of change for ecosystem services (Rounsevell and Harrison, 2016, p. 95) then we can also anticipate that it will influence the direction of this change.

Importantly this framing is not inevitable. It is the product of human choice. Neo-Malthusian framings of food issues have been contested throughout the long history of Malthusianism and neo-Malthusianism. In his Essay on Population (1798), Thomas Robert Malthus predicted that population growth would outstrip food production and lead to famine. Malthus' warnings were proven wrong when new scientific techniques and an increase in agricultural land enabled food supply to outstrip population growth in the 19th Century. A neo-Malthusian narrative then emerged that holds that population is still to be viewed as a problem (though limited to one facing the "poor"), but that mass poverty and famine can be prevented via technology and population control via family planning development efforts (Buttel, 2000). If neo-
Malthusianism is the frame through which the food system problem is configured, technological optimism offers the solution. The two are flip sides of the same coin. Technological optimism proposes that novel technologies lead not only to technical, but also social, political, and even moral progress (Smith and Marx, 1994). Leo Marx (2010) argues that technological optimism extends back to the Enlightenment view of progress; that from its inception, the idea of progress has been tightly bound up with the accelerating rate of scientific and mechanical innovation. Marx argues that by the late 19th C, the idea of progress had become a comprehensive worldview within which the mechanic arts were valued as the means of arriving at not just technical but also social and political ends. This view is clear, for instance, in the view found in our dataset that digital agriculture will alleviate poverty and address unemployment.

Indeed, the texts on digital agriculture produced by the World Bank, FAO, and OECD rehearse neo-Malthusianism and retain key elements of the industrial agriculture and food system models. The role of technological progress in achieving food security and improved social outcomes remains central in descriptions of technologies such as sensors that help farmers understand the complexity of local agricultural systems. Technological optimism comes forward in visions of peasant farmers in remote locations of Africa leveraging smartphone applications to manage their farms and contribute to ecosystem services through responsiveness to local community needs. As we can see from this example, the role of society in these narratives remains important; the FAO, OECD, and World Bank demonstrate views of technologies as necessarily embedded in social contexts. The texts also discuss ways that social structures may need to adapt in order to feed the world. The World Bank says explicitly that "[t]echnology alone is not a silver bullet" (Ghannam, 2017) and the FAO talks about broader changes that are needed to tackle "the root causes of hunger and malnutrition through transformative changes to our food system" (FAO, 2018b, p. 5). However, priority is given in the texts to the argument that peasant farmers become part of existing global food systems through the digital agricultural transition by gaining access to digital tools and infrastructure (e.g. internet) and producing more food. This priority fits into the neo-Malthusian narrative and may contribute to technological lockin within dominant industrial agriculture and food system models (Clapp and Ruder, 2020).

This linkage between technological change and the achievement of social and political ends attracts criticism. For instance, some scholars have voiced concern about the focus on unequal access to technology, as it may gloss over other causes and kinds of inequity that may be reproduced if digital agricultural tools are adopted within existing knowledge-power structures (Bronson, 2018; Carolan, 2017). Others take on neo-Malthusianism more broadly. For instance, political economist Frederick Buttel (2000) argues that neo-Malthusian approaches to food systems "circumvent population-resource contradictions through increasing production, which essentially serves to bolster the legitimacy of prevailing institutions by providing a technological substitute for social reform" (p. 3). According to Buttel, if "poverty is conceptualized primarily as a result of a lack of economic growth and capital investment" then "investments in agricultural R\&D ... must play a role in the hunger alleviation toolkit" (p. 5), at the expense of investments addressing the social and political causes of hunger. Marx (2010) similarly suggests that the problem with technological optimism is that it reifies technologies and obfuscates the complex social or sociotechnical causes of complex problems:

As compared with other means of reaching our social goals, the technological has come to seem the most feasible, practical, and economically viable. It relieves the citizenry of onerous decisionmaking obligations and intensifies their gathering sense of political impotence. The popular belief in technology as a-if not the-primary force shaping the future is matched by our increasing reliance on instrumental standards of judgment, and a corresponding 
neglect of moral and political standards, in making judgments about the direction of society (p. 577).

In this way, critics like Buttel and Leo Marx, along with others (Scanlan, 2013; Scanlan et al., 2010; Fairbairn and Guthman, 2020), suggest that viewing population growth as the primary challenge leads narrowly toward necessarily limited technology-led food production as the solution at the expense of addressing systemic and social problems. Sen (1982) similarly discusses how famines are rarely caused by a lack of food per se, but by a lack of entitlement to food caused by inequality. He argues that in many cases, the solution is not necessarily to produce more food but to distribute food more equitably.

Linnér (2003) goes further in her critique, suggesting that the neoMalthusian framing of food system challenges is not only limited but, in fact, actively works to reproduce inequitable food system relations characteristic of industrial food production. She writes that since the 1990s, neo-Malthusians have been multinational companies, led by Monsanto, who promote genetically modified crops as the answer to the nutritional needs of the 3 billion people facing food insecurity. According to her analysis, genetically modified crops were initially developed in the 1980s for affluent farmers in the United States. However, with increasing opposition to their use in the early aughts, Monsanto embraced the humanitarian rhetoric of the neo-Malthusians with slogans such as: "Worrying about future generations won't feed them. Biotechnology will” (p. 203). In Linnér's view, biotechnologies have been harmful to the peasant farmers and societies they purport to help.

Critiques of neo-Malthusian approaches to food security also appear within some high-level policy documents. For example, the International Panel of Experts on Food Systems (IPES) has the mandate to suggest food system reform with sustainability (broadly defined) as a "benchmark." It argues that food production practices that emphasize intensified production via technology and mono-cropping are "driving environmental degradation, loss of vital ecosystem services, economic hardship for smallholders, socio-economic inequities, and debilitating health impacts and food insecurity for many" (IPES, 2016, p. n.p.). The IPES argues that "a new paradigm is required, rooted in fundamentally different relationships between agriculture and the environment, between food systems and society" (ibid). Similarly, the report of the International Assessment of Agricultural Knowledge, Science and Technology for Development (IAASTD, 2009) advocates reducing the vulnerabilities of the global food system through locally based social innovation and agroecological principles like local knowledge and biodiversity. For a review of these principles see Pimbert (2015).

What, then, of digital agriculture's ability to enhance provisioning, regulation and maintenance, and cultural ecosystem services? If the World Bank, OECD, and FAO consider these enhancements as primarily driven by technological innovation inscribed within existing industrial agriculture and food systems (a concern also raised for other Agriculture 4.0 technologies such as cellular agriculture and plant based protein - Broad, 2019), how do we reconcile this argument with others which critique the industrial agriculture and food system as threatening to regulation and maintenance and cultural ecosystem services? In the documents we analysed, there is no appearance of alternative narratives of the future where social and political innovation enable transitions away from the industrial production model. Nevertheless, digital agricultural technologies could be deployed in alternative visions too, such as in agroecological and circular food systems and short supply chain models (Klerkx et al., 2019; Klerkx and Rose, 2020; Lioutas and Charatsari, 2020; Clapp and Ruder, 2020) - albeit differently than is currently imagined in the documents included in our sample.

Making room for a digitalization of agriculture which lends itself to sustainability, broadly defined, requires active consideration of what assumptions about agriculture, environment and society are put forward in documents that describe the digital agricultural revolution. To date, it does not appear that the ecosystem services literature has engaged in reflection about assumptions about agricultural success defined by productivity gain and efficiency. In a systematic review of ecosystem services literature that took up food security questions, CruzGarcia et al. (2016) found that "most articles assumed that food security would improve by increasing crop productivity, but this hypothesis remained untested" (p.28). It appears, then, that there would be value in taking up a greater diversity of descriptions of the role of emergent technologies in enabling industrial and alternative food system futures as a first step towards evaluating the potential impact of digital agriculture on ecosystem services. Several commentators have argued that this requires an approach of "responsible innovation" which invests in efforts to broaden imaginations about the future and includes diverse perspectives on digital agriculture and the ecosystems we live in (Eastwood et al., 2019; Klerkx and Rose, 2020; Rose and Chilvers, 2018; Scholz et al., 2018; van der Burg et al., 2019; Bronson, 2018; Clapp and Ruder, 2020;Rose et al., 2021).

\section{Conclusion}

In analyzing visions of the future of digital agriculture articulated by the FAO, OECD and World Bank, we presuppose that technologies take shape in complex social contexts including the ways that people imagine them. Because the FAO, OECD and World Bank play an important role in shaping the outlook on the future of agriculture worldwide, we analyzed documents produced by these institutions. We find that within these institutional documents, a digital agricultural future is described as one much like the present, "tweaked" (IPES, 2016) rather than substantively reformed. Despite some diversity in the narratives we encountered in our dataset, the dominant narrative among the texts is one of digital technology as a solution to the long-standing problem of food shortage. These organizations' texts do not explicitly consider other social, institutional, behavioral, structural, or political changes that could also contribute to food security in the future and which would address existing inequities in the distribution of healthy food. The future visions displayed thus leave alternative solutions to food security issues largely untouched, and evoke a vision of a technological fix within an industrial production model.

Despite critiques of these visions from scholars and some important international bodies, the ecosystem services literature to date appears weighted toward emphasis on amending productivist agriculture for reduced use of chemicals with a primary goal of increasing food production (Cruz-Garcia et al., 2016, p. 28). Nevertheless, we know that food production practices aimed at increasing yields often occur at the expense of regulation and maintenance ecosystem services such as regulation of soil quality and carbon sequestration. This should compel us to think critically about narratives of digital agriculture that favour maximizing food output alone though a technological fix within an industrial production model. This framing of the problem and solution can mask over the ways that humans choose not only which technologies to develop but also how to deploy them. With this view of human agency in mind, digital agricultural innovations deserve a careful assessment of the contribution they can make to solving the grand challenges of the 21st century. It is critical to think carefully about social and technological change in agriculture. Can we imagine uses of emergent digital technologies that do not simply reproduce existing systems? In what specific contexts do we see digital tools applied, and significantly, according to which principles (e.g. productivity versus biodiversity)? What are the characteristics of the social context in which the hopes attached to these technologies have most chance to be realized? Ecosystem services researchers have much to offer here, by considering the implications of different models of digitalization of agriculture into the future, doing impact and trade-off analyses of digital agriculture and its relation to ecosystem services in different kinds of future food systems. These analyses can inform processes of responsible innovation. 


\section{Funding}

No specific funding sources were used

\section{Declaration of Competing Interest}

The authors declare that they have no known competing financial interests or personal relationships that could have appeared to influence the work reported in this paper.

\section{Appendix 1. Supplementary data}

Supplementary data to this article can be found online at https:// doi.org/10.1016/j.ecoser.2020.101183.

\section{References}

Akhtman, Y., Golubeva, E., Tutubalina, O., Zimin, M., 2017. Applications of hyperspectural images and ground data for precision farming. Geogr. Environ. Sustain 104, 117-128.

Barrett, H., Rose, D.C., 2020. Perceptions of the fourth agricultural revolution: what's in, what's out, and what consequences are anticipated? Sociologia Ruralis. https://doi. org/10.1111/soru.12324. In press.

Berkhout, F., 2006. Normative expectations in systems innovation. Technol. Anal. Strateg. Manage. 18, 299-311.

Bongiovanni, R., Lowenberg-DeBoer, J., 2004. Precision agriculture and sustainability. Precis. Agric. 5, 359-387.

Borup, M., Brown, N., Konrad, K., Van Lente, H., 2006. The sociology of expectations in science and technology. Technol. Anal. Strateg. Manage. 18, 285-298.

Braun, V., Clarke, V., 2006. Using thematic analysis in psychology. Qual. Res. Psychol. 3, 77-101.

Bronson, K., 2019. The Digital Divide and How it Matters for Canadian Food System Equity. Can. J. Commun. 44.

Bronson, K., 2018. Smart Farming: Including Rights Holders for Responsible Agricultural Innovation. Technol. Innov. Manag. Rev. 8, 7-14. https://doi.org/10.22215/timreview/1135.

Broad, G.M., 2019. Plant-based and cell-based animal product alternatives: An assessment and agenda for food tech justice. Geoforum 107, 223-226.

Broad, G.M., 2020a. Know Your indoor farmer: Square roots, techno-local food, and transparency as publicity. Am. Behav. Sci. https://doi.org/10.1177/ 0002764220945349. In press.

Broad, G.M., 2020b. Making meat, better: The metaphors of plant-based and cell-based meat innovation. Environ. Commun. https://doi.org/10.1080/17524032.2020. 1725085. In press.

Buttel, F.H., 2000. Ending hunger in developing countries. Contemp. Sociol. 29, 12.

Carolan, M., 2017. Publicising food: big data, precision agriculture, and co-experimental techniques of addition. Sociol. Rural. 57, 135-154. https://doi.org/10.1111/soru. 12120.

Chiles, R.M., 2013. If they come, we will build it: in vitro meat and the discursive struggle over future agrofood expectations. Agr. Hum. Values 30, 511-523.

Clapp, J., Ruder, S.-L., 2020. Precision technologies for agriculture: Digital farming, geneedited crops, and the politics of sustainability. Glob. Environ Polit. 20, 49-69.

Cruz-Garcia, G.S., Sachet, E., Vanegas, M., Piispanen, K., 2016. Are the major imperatives of food security missing in ecosystem services research? Ecosyst. Serv. 19, 19-31.

Deichmann, U., Goyal, A., Mishra, D., 2016. Will Digital Technologies Transform Agriculture in Developing Countries? (No. Research Working Paper No. 7669). World Bank, Washington DC.

Eastwood, C., Klerkx, L., Ayre, M., Dela Rue, B., 2019. Managing socio-ethical challenges in the development of smart farming: from a fragmented to a comprehensive approach for responsible research and innovation. J. Agric. Environ. Ethics. 32, 741-768.

El Bilali, H., Allahyari, M.S., 2018. Transition towards sustainability in agriculture and food systems: role of information and communication technologies. Inf. Process. Agric. 5, 456-464.

FAO, 2018a. Status of Implementation of E-agriculture in Central and Eastern Europe and Central Asia - Insights from selected countries in. Europe and Central Asia, Budapest.

FAO, 2018b. FAO's Work on Agricultural Innovation: Sowing the seeds of transformation to achieve the SDGs. Rome.

Fairbairn, M., Guthman, J., 2020. Agri-food tech discovers silver linings in the pandemic. Agr. Hum. Values 37, 587-588.

FAO, 2017. Success Stories in Information and Communication Technologies for Agriculture and Rural Development. Second Edition.

Gebbers, R., Adamchuk, V.I., 2010. Precision agriculture and food security. Science 327, 828-831.

Ghannam, Nadine Shamounki, 2017. Precision Farming Enables Climate-Smart Agribusiness (No. Note 46), EMCompass: Fresh Ideas About Business in Emerging Markets. World Bank, Washington DC.

Gidley, J.M., 2017. The Future: A Very Short Introduction. Oxford University Press.

Hajer, M., Laws, D., 2006. Ordering through Discourse. Teoksessa Michael Moran \& Martin Rein \& Robert Goodin (toim.), in: Moran, T.M., Rein, M., Goodin, R. (Eds.),
The Oxfrod Handbook of Public Policy. Oxford University Press, Oxford.

Hekkert, M.P., Janssen, M.J., Wesseling, J.H., Negro, S.O., 2020. Mission-oriented innovation systems. Environ. Innov. Soc. Transit. 34, 76-79.

Hunt Jr, E.R., Daughtry, C.S., 2018. What good are unmanned aircraft systems for agricultural remote sensing and precision agriculture? Int. J. Remote Sens. 39, 5345-5376.

IAASTD, 2009. Agriculture at a Crossroads: synthesis report. Island Press, Washington DC.

IPES, 2016. From Uniformity to Diversity: a paradigm shift from industrial agriculture to diversified agroecological systems. International Panel of Experts on Sustainable Food Systems.

Jakku, E., Taylor, B., Fleming, A., Mason, C., Fielke, S., Sounness, C., Thorburn, P., 2019. "If they don't tell us what they do with it, why would we trust them?" Trust, transparency and benefit-sharing in Smart Farming. NJAS-Wagening. J. Life Sci. 90, 100285.

Jasanoff, S., Kim, S.-H., 2015. Dreamscapes of Modernity: Sociotechnical Imaginaries and the Fabrication of Power. University of Chicago Press.

Kamilaris, A., Kartakoullis, A., Prenafeta-Boldú, F.X., 2017. A review on the practice of big data analysis in agriculture. Comput. Electron. Agric. 143, 23-37.

Karlsson, L., Naess, L.O., Nightingale, A., Thompson, J., 2018. 'Triple wins' or 'triple faults'? Analysing the equity implications of policy discourses on climate-smart agriculture (CSA). J. Peasant Stud. 45, 150-174.

Klerkx, L., Begemann, S., 2020. Supporting food systems transformation: The what, why, who, where and how of mission-oriented agricultural innovation systems. Agric. Syst. 184, 102901.

Klerkx, L., Jakku, E., Labarthe, P., 2019. A review of social science on digital agriculture, smart farming and agriculture 4.0: New contributions and a future research agenda. NJAS - Wagen. J. Life Sci. 90-91, 100315.

Klerkx, L., Rose, D., 2020. Dealing with the game-changing technologies of Agriculture 4.0: How do we manage diversity and responsibility in food system transition pathways? Glob. Food Secur. 24, 100347.

Klytchnikova, I.I., Sadler, M.P., Townsend, R., Edmeades, S., Choudhary, V., Hussain, S. Kray, H.A., Fernandes, E.C.M., Moses, E.D., Cantrell, J.T., Morales, X.Z., Pietrowski, M.S., 2015. Future of Food : Shaping a Climate-smart Global Food System No. 100046 The World Bank.

Kuch, D., Kearnes, M., Gulson, K., 2020. The promise of precision: datafication in medicine, agriculture and education. Policy Stud. 41, 527-546.

Linnér, B.-O., 2003. The Return of Malthus: Environmentalism and Post-war Populationresource Crises. White Horse Press.

Lioutas, E.D., Charatsari, C., 2020. Smart farming and short food supply chains: are they compatible? Land Use Policy 94, 104541.

Macnaghten, P., Davies, S.R., Kearnes, M., 2015. Understanding public responses to emerging technologies: a narrative approach. J. Environ. Policy Plan. 1-19.

Maity, S., 2018. What is digital farming ? Discussion with Tobias Menne, head of Digital Farming at BASF. Capgemini Worldw. URL https://www.capgemini.com/2018/04/ what-is-digital-farming-discussion-with-tobias-menne-head-of-digital-farming-basf/ (accessed 7.1.20).

Marx, L., 2010. Technology: The emergence of a hazardous concept. Technol. Cult. 51, 561-577.

McBratney, A., Whelan, B., Ancev, T., Bouma, J., 2005. Future directions of precision agriculture. Precis. Agric. 6, 7-23.

Mogili, U.R., Deepak, B., 2018. Review on application of drone systems in precision agriculture. Procedia Comput. Sci. 133, 502-509.

Mouat, M.J., Prince, R., Roche, M.M., 2019. Making Value Out of Ethics: The Emerging Economic Geography of Lab-grown Meat and Other Animal-free Food Products. Econ. Geogr. 95, 136-158.

Nielson, D., Meng, Y.-T., Buyvolova, A., Hakobyan, A., 2018. Unleashing the Power of Digital on Farms in Russia - and Seeking Opportunities for Small Farms. The World Bank.

OECD, 2018a. Summary Record: Global Forum on Agriculture 14-15 May 2018 Digital technologies in food and agriculture: Reaping the benefits. OECD.

OECD, 2018b. How digital technologies are impacting the way we grow and distribute food. OECD, Rome, Italy.

OECD, 2018c. The CAP post-2020 Farm Sustainability Tool for Nutrients (FaST). OECD.

OECD, 2016. Is precision agriculture the start of a new revolution?, in: Farm Management Practices to Foster Green Growth. OECD Publishing, Paris.

Patrício, D.I., Rieder, R., 2018. Computer vision and artificial intelligence in precision agriculture for grain crops: a systematic review. Comput. Electron. Agric. 153, 69-81.

Pigford, A.-A.-E., Hickey, G.M., Klerkx, L., 2018. Beyond agricultural innovation systems? Exploring an agricultural innovation ecosystems approach for niche design and development in sustainability transitions. Agric. Syst. 164, 116-121.

Pimbert, M., 2015. Agroecology as an Alternative Vision to Conventional Development and Climate-smart Agriculture. Development 58, 286-298. https://doi.org/10.1057/ s41301-016-0013-5.

Poppe, K., Wolfert, J., Verdouw, C., Renwick, A., 2015. A European perspective on the economics of big data. Farm Policy J. 12, 11-19.

Rose, D.C., Chilvers, J., 2018. Agriculture 4.0: broadening responsible innovation in an era of smart farming. Front. Sustain. Food Syst. 2, 87.

Rose, D.C., Wheeler, R., Winter, M., Lobley, M., Chivers, C.A., 2021. Agriculture 4.0: Making it work for people, production, and the planet. Land Use Policy 100, 104933.

Rossel, R.A.V., Bouma, J., 2016. Soil sensing: A new paradigm for agriculture. Agric. Syst. 148, 71-74.

Rotz, S., Duncan, E., Small, M., Botschner, J., Dara, R., Mosby, I., Reed, M., Fraser, E.D., 2019. The politics of digital agricultural technologies: a preliminary review. Sociol. Rural. 59, 203-229.

Rounsevell, M.D., Harrison, P.A., 2016. Briefing Note 7.2 Drivers of change for ecosystem services. Routledge Handb. Ecosyst. Serv. 94. 
Scanlan, S.J., 2013. Feeding the Planet or Feeding Us a Line? Agribusiness, 'Grainwashing'and Hunger in the World Food System. Int. J. Sociol. Agric. Food 20. Scanlan, S.J., Jenkins, J.C., Peterson, L., 2010. the scarcity fallacy. Contexts 9, 34-39.

Scholten, M.C.T., de Boer, I.J.M., Gremmen, B., Lokhorst, C., 2013. Livestock Farming with Care: towards sustainable production of animal-source food. NJAS - Wagen. J Life Sci. 66, 3-5.

Scholz, R.W., Bartelsman, E.J., Diefenbach, S., Franke, L., Grunwald, A., Helbing, D., Hill, R., Hilty, L., Höjer, M., Klauser, S., 2018. Unintended side effects of the digital transition: European scientists' messages from a proposition-based expert round table. Sustainability 10, 2001.

Sen, A., 1982. Poverty and Famines: An Essay on Entitlement and Deprivation. Oxford University Press.

Shamshiri, RR., Weltzien, C., Hameed, I.A., Yule, JI., Grift, ET., Balasundram, S.K. Pitonakova, L., Ahmad, D., Chowdhary, G., 2018. Research and development in agricultural robotics: A perspective of digital farming. Int. J. Agric. \& Biol. Eng. 11 (4), 1-14.

Skvortcov, E., Skvortsova, E., Sandu, I., Iovlev, G., 2018. Transition of agriculture to digital, intellectual and robotics technologies. Econ. Reg. 1, 1014-1028.

Smith, M.J., 2020. Getting value from artificial intelligence in agriculture. Anim. Prod. Sci. 60, 46-54.

Smith, M.R., Marx, L., 1994. Does Technology Drive History?: The Dilemma of Technological Determinism. Mit Press.

Snow, D.A., Benford, R.D., 1992. Master frames and cycles of protest. Front. Soc. Mov. Theory 133, 155.

Sonka, S., 2015. Big Data: from hype to agricultural tool. Farm Policy J. 12, 1-9.

Tomlinson, I., 2013. Doubling food production to feed the 9 billion: a critical perspective on a key discourse of food security in the UK. J. Rural Stud. 29, 81-90.

Treinen, S., van der Elstraeten, A., 2018. Gender and ICTs - Mainstreaming Gender in the Use of Information and Communication Technologies (ICTs) for Agriculture and Rural Development. FAO, Rome.

van der Burg, S., Bogaardt, M.-J., Wolfert, S., 2019. Ethics of smart farming: current questions and directions for responsible innovation towards the future. NJASWagening. J. Life Sci. 90-91, 100289.

Verdouw, C., Wolfert, S., Tekinerdogan, B., 2016. Internet of Things in agriculture. CAB Rev Perspect. Agric. Vet. Sci. Nutr. Nat. Resour. 11, 1-12.

Weersink, A., Fraser, E., Pannell, D., Duncan, E., Rotz, S., 2018. Opportunities and challenges for big data in agricultural and environmental analysis. Annu. Rev. Resour. Econ. 10, 19-37.

World Bank, 2017. ICT in Agriculture (Updated Edition): Connecting Smallholders to Knowledge, Networks, and Institutions. World Bank, Washington DC.

World Bank, 2015. Big Data Solutions: Innovative Approaches to Overcoming Agricultural Challenges in Developing Nations by Harnessing the Power of Analytics. World Bank, Washington DC.

World Bank Group, 2016. Big Data Innovation Challenge: Pioneering Approaches to DataDriven Development. World Bank, Washington DC.

World Bank Group, China Development Bank, 2017. Leapfrogging: The Key to Africa's Development? From Constraints to Investment Opportunities, World Bank, Washington DC.

Zhao, G., Liu, S., Lopez, C., Lu, H., Elgueta, S., Chen, H., Boshkoska, B.M., 2019. Blockchain technology in agri-food value chain management: a synthesis of applications, challenges and future research directions. Comput. Ind. 109, 83-99. 